PART 7. OTHER LIBRARY ACTIVITIES 


\title{
Use of Computers in Small Libraries
}

\author{
E. Sachtschal \\ European Southern Observatory \\ Karl-Schwarzschild-Str. 2 \\ D-8046 Garching bei München, F.R. Germany
}

\section{Introduction}

The library of the European Southern Observatory exists in its holdings since about 1970. The library is still a small one. It contains about 15-20000 books, 240 journal titles, approximately $70 \mathrm{~m}$ shelf-space for Observatory Publications and has about 220 square meters surface area. With about the same size we have a second library in La Silla in Chile, the mountain where our telescopes are installed. In Garching we have one and a third (!) librarian(s) and in Chile one librarian as staff. The question is: is it possible and is it necessary to computerize such small libraries and how can we do it with such limited personnel? The answer is yes; it is possible and even worthwhile.

The old slogan: "In America everything is better and bigger" influenced also my library. Astronomers coming from the Library of the Baltimore Space Telescope Science Institute sang a hymn of praise as to how fantastically everything works in this totally computerized library. Well, the younger ones praised, while the opinion of the older generation of astronomers was slightly different!! Ergo, not to behave as an old-fashioned conservative librarian, I started to do something in the computer business ; and that is what I would like to talk about today.

I will not use the language of a normal user's manual in its professional explicit approach. Librarians don't even have the time to read such manuals in detail, we did it more using the "do it yourself" method. I will try to show more the librarians' standpoint, how to approach "modernization", how to get over the suffering steps (when you just want to smash your screen), but finally how to enjoy slowly the pleasures of the new system and how even to become fascinated by it .

\section{Preprints and observatory publications on-line}

A Database Machine IDM 500/1 (from Britton-Lee) was acquired for ESO and ST-ECF Archive Management at the ESO Headquarters. Up to now two applications for the library have been developed using OMNIBASE and SMART QUERY software. For all output on paper LATEX document processing software is used. As first application we created a PREPRINT DATABASE which can also be used ON-LINE not only for ESO customers but also for any SPAN user or institutes having a connection to a Packet Switching Network. Many speakers mentioned the handling of preprints already, therefore I start immediately to talk about our: 


\section{Database for periodicals}

As our User's Manual says, the database is a so-called RELATIONAL database which is organised in tables. Each table is quite similar to a printed table in the sense that it is made of columns or fields, and rows and records, which is easy to understand. But only one record taken from one table is listed on the screen. The relational database allows one to connect or join records from different tables sharing some common value. To make the recognition of these common values easier, codes are created: codes for periodicals' titles and suppliers. Five tables are implemented in this prototype database:

1) TITLES providing full titles and associated comments for each periodical.

2) SUPPLIER listing information about suppliers with full addresses; one letter specifying the language to be used for renewal correspondence. $E=$ English, $\mathrm{F}=$ French, $\mathrm{G}=$ German.

3) ORDERING TABLE providing information about the ordering status of the periodicals: which journal is ordered from which supplier. On this table you see codes only for titles and suppliers and the number of copies to be sent to the different libraries and in which mailing mode: DAM - Direct Air Mail, DSM = Direct Surface Mail. Important in this table is the date which follows the word RENEW, which will be the date when a renewal letter is issued automatically.

4) HOLDING TABLE specifying which volumes exist in each ESO-Library. Here you see the code only for the title and abbreviations for the different libraries. An explanation of these abbreviations is shown on the table and later in the Holding list. In the CONT field you have three possibilities: to show whether a publication ceased $=$ blank, whether we stopped a subscription $=$. , or whether the subscription is normally continued $=-$. Since one table can show only one record you have to hit the "Find Next Key" (PF3) in order to enter or find the same title for the second or third library. A place for comments associated with the title in this field is available for mentioning notes such as: continued as or formerly ...

5) ARRIVAL TABLE quoting the issues arriving daily in the library is foreseen but not yet used. We enter our daily incoming journals still into an oldfashioned Kardex until somebody really convinces me that the alternative is worthwhile.

\section{How to query the library database}

There is a special QUERY KEYPAD which looks familiar to the customers of the Space Telescope Science Institute Library in Baltimore, because they use the same software as we do. I only want to mention, leaving out all details, that it is very easy to DELETE or to MODIFY any records or to APPEND any new entries in your database. 
I come back to the formerly mentioned RELATIONAL Database. You have seen for example that the Supplier code appeared in both ORDERING and SUPPLIER tables. This enables the connection of the two tables, to add to each periodical the complete designation and address of the supplier, and conversely to find out all periodicals supplied by a specified vendor. And herewith I come to the:

\section{Document generation from the library database for periodicals}

As mentioned before LATEX is used for all printed output. Just by pressing one button we can produce lists and letters combining the information from the individual tables. The most important list is:

1) THE FINDING LIST OF PERIODICALS IN ESO-LIBRARIES which combines the entries of the HOLDING and TITLE tables. Here appear the crossreferences which we entered in the TITLE table as comments assigned to the title.

2) THE LIBLIST ORDERING shows the connection or relation of three table entries: namely 'TITLES-ORDERING-SUPPLIERS. This list I consider as my "bible". It is produced yearly and helps me to supervise the status of ordering and renewals. I use it for price comparison and claims and many other things.

3) THE LIST OF SUPPLIERS filed alphabetically by supplier names, full addresses and codes.

4) LIST OF TITLES of periodicals also in alphabetical order of names and codes. The arrangement by code is necessary to check whether a code is used or not. The computer does not allow a duplicate application.

5) LIBLIST LA SILLA is the "Bible" for the librarian in La Silla who sees at a glance which periodical she receives directly on the site, in how many copies and from which supplier.

6) THE RENEWAL LETTERS for the time being produced in three languages will be my last example. Here you have the combination or relation of three of our tables: SUPPLIER-TITLES-ORDERING. You see in one group together all titles requested from one supplier with the directions where to send the periodicals, in which mailing mode and where to send the invoice. The small letter for the language entered on the supplier table determines the language of the letter itself.

This "personal" touch of my "machine" is certainly the result of the good cooperation between Francois Ochsenbein and me. He worked on the programming and did the impossible - which I as a crazy librarian wanted him to do - and this among other things went as far as the creation of the multi-language letters. Compliments to him and his patience with me. 
Eso Library - Perlodical Titlea

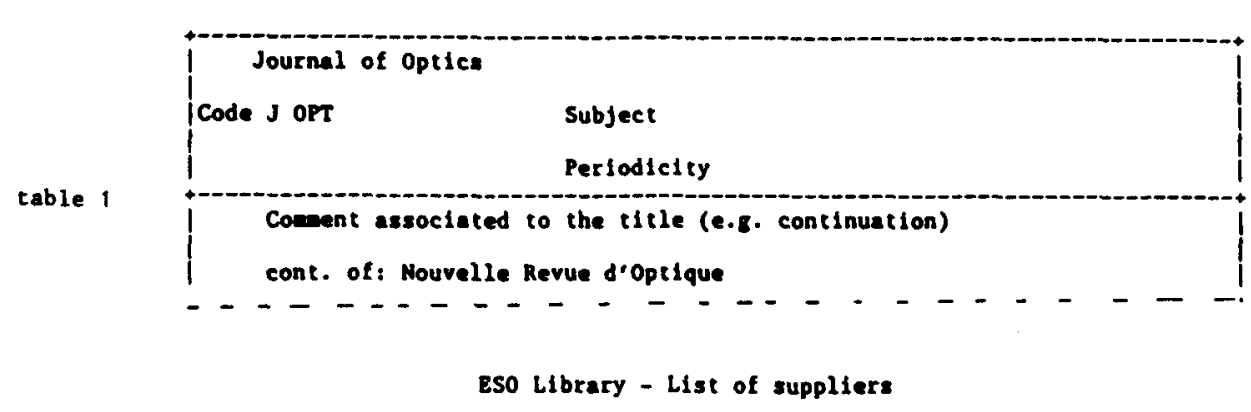

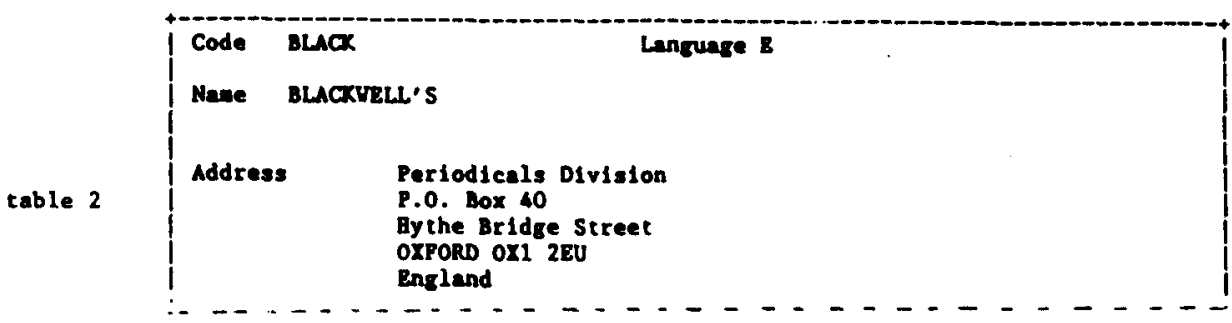

ESO Library - Bolding Table

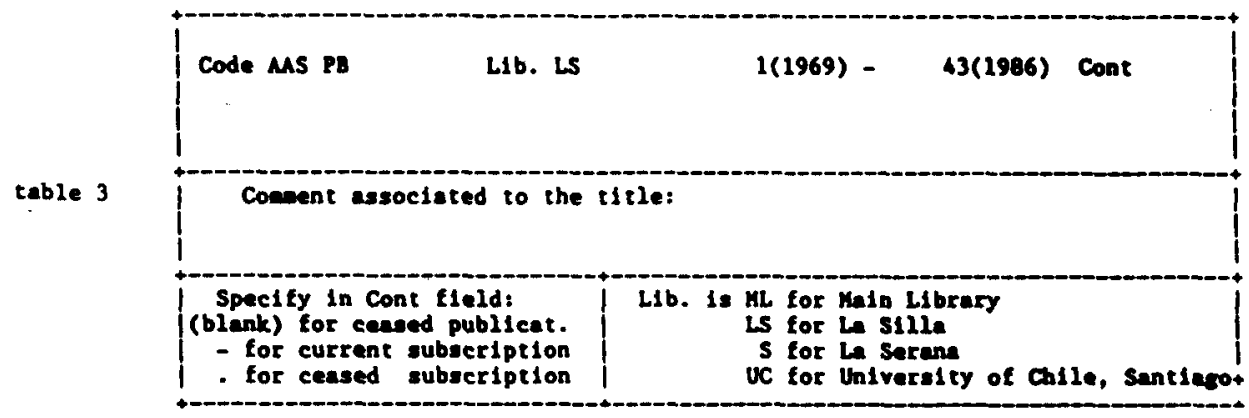

ESO Library - state of periodical orderlng

cable 4

\begin{tabular}{|c|c|c|c|c|c|c|}
\hline \multirow[t]{2}{*}{ Journal AGA } & \multicolumn{6}{|c|}{ Supplier SPRIMG } \\
\hline & Coples & Malling & Cost in & & & \\
\hline $\begin{array}{l}\text { Maln Library } \\
\text { La Sille } \\
\text { Le Sarena } \\
\text { Univ. Chile } \\
\text { Other }\end{array}$ & $\begin{array}{l}1 \\
1 \\
1\end{array}$ & $\begin{array}{l}\text { DSH } \\
\text { DNY } \\
\text { DAY }\end{array}$ & : & $\begin{array}{l}\text { Pron } \\
\text { To } \\
\text { B111 } \\
\text { Rener }\end{array}$ & $\begin{array}{l}25-06-1986, \\
31-12-1988, \\
25-06-1986\end{array}$ & no \\
\hline sus & 3 & & - & & & \\
\hline
\end{tabular}

I have no room to print here all the examples of my overheads shown during the talk. But the attached figure with the four tables I consider as essential for the understanding of this article. 